\title{
Artificial Induction of an Organism Similar to Mycobacterium triviale from Mycobacterium gordonae by Successive Ultraviolet Irradiations
}

\author{
M. TSUKAMURA,' S. MIZUNO,' AND S. TSUKAMURA² \\ The National Chubu Hospital,' and Tsukamura Clinic, ${ }^{2}$ Obu, Aichi, Japan 474
}

\begin{abstract}
An organism phenetically indistinguishable from Mycobacterium triviale was isolated from Mycobacterium gordonae (ATCC 14470) by successive ultraviolet irradiations after three selection steps. From the parent (a smooth-colony-forming, scotochromogenic strain) were isolated: (i) photochromogenic mutants; (ii) rough-colony-forming mutants; and (iii) non-photochromogenic (pigmentless) mutants. In the third step of mutation, some mutants showed simultaneous changes of other characters, e.g., loss of the ability to utilize several carbon sources. After ultraviolet irradiation, mutant colonies comprised 1 to 2 per $10^{3}$ surviving colonies. It was impossible to isolate non-photochromogenic mutants directly from parent scotochromogenic bacteria. Mutants could be isolated only from photochromogenic mutants. This is in marked contrast to a previous work in which non-photochromogenic mutants were isolated directly from parent, scotochromogenic Mycobacterium scrofulaceum.
\end{abstract}

An important purpose of taxonomy is to show phylogenic relationships among microorganisms. If possible pathways of evolution could be reproduced experimentally, investigations would be facilitated.

As an aid to the taxonomic study of mycobacteria, attempts to artificially produce one species from another species were begun with Mycobacterium gordonae, a slowly growing, scotochromogenic species that occurs very commonly in the environment (10) and has been known previously as a tapwater scotochromogen $(8,14)$. An organism was experimentally produced that is similar to $M$. triviale and to another organism resembling $M$. terrae.

\section{MATERIALS AND METHODS}

Strains. The parent, Mycobacterium gordonae Bojalil et al. (1), strain T-12109, was received from the American Type Culture Collection, Rockville, Md., as ATCC 14470. Strains of $M$. triviale Kubica et al. (2), $M$. terrae Wayne (13), and $M$. nonchromogenicum Tsukamura (7) were used for comparison. The sources of these strains were given previously (9). The test strains were cultivated on Ogawa egg medium slants at $37^{\circ} \mathrm{C}$ for 14 days.

Tests. The tests used were described previously (9).

Ultraviolet irradiation. Ultraviolet irradiation was used for inducing mutations in $M$. gordonae T12109. Growing organisms taken from Ogawa egg medium slants were homogenized by $5 \mathrm{~min}$ of shaking in a flask containing glass beads; a 10- or 1-mg (moist weight) $/ \mathrm{ml}$ suspension was then prepared (organisms suspended in $0.067 \mathrm{M}$ phosphate buffer [pH 7.1] containing $0.1 \%$ [vol/vol] Tween 80 ). A series of 10 -fold dilutions was prepared (down to $10^{-7}$ ) from the sus- pension. As an aid for counting the number of viable bacteria before irradiation, a $0.02 \mathrm{ml}$ sample of each $10^{-4}$ to $10^{-7}$ dilution was inoculated into five tubes of Ogawa egg medium by using a spiral loop. The original suspension $(10 \mathrm{ml})$ was then placed in a petri dish $(9-$ $\mathrm{cm}$ diameter) and irradiated by using a germicidal lamp (National GL-15, Matsushita Electric Company, Osaka; $15 \mathrm{~W}$ ) at a distance of $1 \mathrm{~m}$ for $15 \mathrm{~min}$. During irradiation, the suspension was stirred by rotating the dish by hand for $15 \mathrm{~s}$ at intervals of $1 \mathrm{~min}$. The irradiation was carried out in a dark room, to avoid photoreactivation, at room temperature $\left(20\right.$ to $\left.25^{\circ} \mathrm{C}\right)$. After irradiation, the suspension and a $10^{-1}$ dilution of it were inoculated into 30 to 50 tubes of Ogawa egg medium with a spiral loop that delivered a $0.02-\mathrm{ml}$ sample. The inoculated tubes were stoppered with rubber caps with pin holes and incubated at $37^{\circ} \mathrm{C}$ for 14 to 21 days in the dark. Under the conditions used, the number of viable bacteria fell to $10^{-6}$ to $10^{-7}$ after irradiation. To test for photochromogenicity or nonphotochromogenicity of nonpigmented colonies in the dark, each single colony was inoculated onto two Ogawa egg medium slants, one of which was incubated at $37^{\circ} \mathrm{C}$ in the dark; the other was exposed to light. After incubation for 14 days, pigmentation of colonies was observed.

Numerical classification. Numerical classification was carried out using the same 88 characters and the same techniques as used previously (9). From the calculated matching coefficients, clustering was determined by a single-linkage method.

Designation of mutants. To simplify the description, photochromogenic mutants, rough-colony-forming (R-type) mutants, and non-photochromogenic (pigmentless) mutants were designated $\mathrm{P}, \mathrm{R}$, and $\mathrm{N}$, respectively; the numbers indicate the colony number (mutant number). For example, P1, P2, and P3 represent three photochromogenic mutants isolated from the parent, scotochromogenic strain. 


\section{RESULTS}

The selection steps after ultraviolet irradiation are shown in Fig. 1. An organism phenetically indistinguishable from $M$. triviale was isolated by steps $a, b$, and $c_{1}$, and an organism resembling $M$. terrae was isolated by steps a, b, and $c_{2}$.

At step a, photochromogenic mutants were isolated from parent, smooth-colony-forming, scotochromogenic bacteria at a rate of $2.4 / 10^{3}$ surviving colonies (27 photochromogenic colonies appeared among 11,160 scotochromogenic surviving colonies). The mutants appeared as pigmentless colonies in the dark, and all were shown to be photochromogenic after incubation under light. Three strains (P1, P2, and P3) of the photochromogenic mutants were tested for their biological and biochemical characters, and one of them (P2) was used for the next ultraviolet irradiation experiment. Rough-colony-forming (R-type) mutants were isolated from the P2 strain at a rate of $1.5 / 10^{3}$ surviving colonies (23 per ca. 15,000 surviving colonies). Three strains (P2-R1, P2-R2, and P2-R3) of the R-type photochromogenic mutants were tested for their characters, and two strains (P2-R1 and P2-R3) were used for the next ultraviolet irradiation experiment. Non-photochromogenic mutants were isolated from these strains at rates of 2.4 and $2.0 / 10^{3}$ surviving colonies, respectively $(8$ per ca. 3,300 and 6 per ca. 3,000 surviving colonies, respectively). Fourteen strains of these mutants (P2-R1-N1 to P2-R1-N8 and P2-R3-N1 to P2-R3-N6) were tested for their characters.

In contrast to the parent strain of $M$. gordonae, which is able to utilize glucose, acetate, pyruvate, $n$-propanol, $n$-butanol, and iso-butanol as the sole source of carbon in the presence of $\mathrm{NH}_{4}$-nitrogen, 12 of the 14 mutants lacked the capacity to utilize some of these carbon compounds. One strain (P2-R1-N4) did not utilize any of these carbon compounds; the characteristics of the strain were very similar to those of the $M$. triviale strains (Table 1). The colony of another (P2-R1-N7) exhibited an appearance intermediate between the R-type and the $\mathrm{S}$ type. It resembled the $S$-type but formed smooth, somewhat dry colonies, although other mutant colonies were rough and dry. The colonies of the parent strain and $\mathrm{P}$ mutants were smooth and very wet. The mutant P2-R1-N7 grew more slowly than the other mutants. The other strains showed abundant growth on Ogawa egg medium slants after 7 days, whereas the mutant showed such growth only after 10 days, and its colony appearance was similar to that of M. terrae.

A comparison of the characters of the mutants and the parent strain of $M$. gordonae and the reference strains of $M$. nonchromogenicum, $M$. terrae, and $M$. triviale is shown in Table 1 .

Other experiments to obtain non-photochromogenic (pigmentless) mutants were also carried out. In one, R-type mutants were isolated and then photochromogenic mutants were isolated from them. Non-photochromogenic mutants were, in turn, isolated from the latter (Fig. 1). The mutants were isolated at every step at a rate of 1 to $2 / 10^{3}$ surviving colonies. The $\mathrm{R}$-type, non-photochromogenic mutants thus obtained utilized glucose, acetate, succinate, and pyruvate in the presence of glutamate-nitrogen and utilized $n$-butanol or iso-butanol in the presence of $\mathrm{NH}_{4}$-nitrogen.

It was difficult to isolate non-photochromogenic (pigmentless) mutants from S-type photochromogenic mutants, although it could be

Parental, S-type sco- $\stackrel{a}{\longrightarrow}$ S-type photochromo- $\stackrel{b}{\longrightarrow}$ R-type photo- $\stackrel{c_{1}}{\longrightarrow}$ R-type non-photochromogen tochromogen

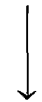

R-type scotochromogen

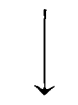

R-type photochromogen

R-type non-photochromogen

$$
\text { gen (P2) }
$$

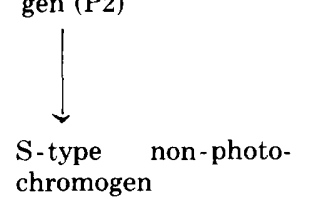

FIG. 1. Artificial induction of mutants similar to or resembling $M$. triviale and $M$. terrae from $M$. gordonae by ultraviolet irradiations. 
TABLE 1. Comparison of characters of various mutants isolated from $M$. gordonae and strains of $M$. triviale, $M$. terrae, and $M$. nonchromogenicum ${ }^{\prime}$

\begin{tabular}{|c|c|c|c|c|c|c|c|c|c|c|}
\hline Character & $\begin{array}{c}\text { T- } \\
12109\end{array}$ & $\mathrm{P} 2$ & $\mathrm{P} 2-\mathrm{R} 1$ & $\begin{array}{l}\text { P2- } \\
\text { R1-N4 }\end{array}$ & $\begin{array}{l}\mathrm{P} 2 \\
\mathrm{R} 1 \cdot \mathrm{N} 7\end{array}$ & 37013 & 37004 & 38013 & 38008 & 09003 \\
\hline Rough colonies & - & - & + & + & - & + & + & - & - & - \\
\hline Photochromogenicity & - & + & + & - & - & - & - & - & - & - \\
\hline Colony pigmentation in the dark & + & - & - & - & - & - & - & - & - & - \\
\hline \multicolumn{11}{|l|}{ Resistance to $\mathrm{NH}_{2} \mathrm{OH} \cdot \mathrm{HCl}(0.5$} \\
\hline $\mathrm{mg} / \mathrm{ml} \mathbf{l} \ldots \ldots \ldots \ldots \ldots$ & - & + & - & + & + & + & + & + & + & + \\
\hline Tween hydrolysis at 7 days ... & - & + & - & - & - & - & - & - & - & - \\
\hline$\alpha$-Esterase $\ldots \ldots \ldots \ldots$ & - & + & + & - & - & - & - & - & - & - \\
\hline$\beta$-Esterase $\ldots \ldots$ & + & + & + & + & - & - & + & + & + & + \\
\hline Acid phosphatase & - & - & - & - & - & + & + & + & + & + \\
\hline$\beta$-Galactosidase & - & - & - & - & - & - & - & - & + & + \\
\hline Nitrate reduction ( 24 hours) & - & - & - & - & - & + & + & - & - & - \\
\hline Three-day arylsulfatase $\ldots \ldots \ldots$ & + & + & + & + & + & + & + & - & - & - \\
\hline Two-week arylsulfatase . . . . . . & + & + & + & + & + & + & + & + & - & + \\
\hline Nicotinamidase $\ldots \ldots \ldots \ldots \ldots$ & - & - & - & - & - & - & - & - & - & + \\
\hline Pyrazinamidase $\ldots \ldots \ldots$ & - & - & - & - & - & - & - & - & - & + \\
\hline Glucose as C source ${ }^{h}$ & + & + & + & - & - & - & - & - & - & - \\
\hline$n$-Propanol as C source ${ }^{b}$ & + & + & + & - & - & - & - & + & - & - \\
\hline$n$-Butanol as C source ${ }^{b}$ & + & + & + & - & + & - & - & + & - & - \\
\hline iso-Butanol as $\mathrm{C}$ source ${ }^{b} \ldots \ldots$ & + & + & + & - & - & - & - & + & - & - \\
\hline Acetate as C source $^{b}$ & + & + & + & - & + & - & + & + & - & + \\
\hline Pyruvate as $\mathrm{C}$ source $^{b} \ldots \ldots$ & + & + & + & - & + & - & + & + & - & + \\
\hline \multicolumn{11}{|l|}{ Glucose as C source (glutamate- } \\
\hline $\mathbf{N}) \ldots \ldots \ldots \ldots \ldots \ldots$ & + & + & + & - & - & - & - & - & - & - \\
\hline \multicolumn{11}{|l|}{$\begin{array}{c}\text { Acetate as } C \text { source (gluta- } \\
\text { mate-N) }\end{array}$} \\
\hline \multicolumn{11}{|l|}{ Succinate as $\mathrm{C}$ source (gluta- } \\
\hline \multicolumn{11}{|l|}{ Pyruvate as $\mathrm{C}$ source (gluta- } \\
\hline mate-N) $\ldots \ldots \ldots \ldots$ & + & + & + & - & + & - & + & + & - & + \\
\hline Growth on Sauton agar ....... & + & + & + & - & + & - & - & + & - & + \\
\hline Nicotinamide as $\mathrm{N}$ source ..... & + & + & + & - & - & - & - & - & - & + \\
\hline Nitrate as $\mathbf{N}$ source $\ldots \ldots \ldots \ldots$ & + & + & - & - & - & - & - & - & - & - \\
\hline Strong acid-fastness $\ldots \ldots \ldots$ & + & + & + & + & + & + & + & + & + & + \\
\hline Weak acid-fastness $\ldots \ldots \ldots$ & + & + & + & + & + & + & + & + & + & + \\
\hline Presence of rod form $\ldots \ldots \ldots$ & + & + & + & + & + & + & + & + & + & + \\
\hline Cord .............. & - & - & - & - & - & - & - & - & - & - \\
\hline Fragmenting mycelium . . . . . & - & - & - & - & - & - & - & - & - & - \\
\hline Permanent mycelium . . . . . . . & - & - & - & - & - & - & - & - & - & - \\
\hline Growth after 3 days & - & - & - & - & - & - & - & - & - & - \\
\hline \multicolumn{11}{|l|}{ Tolerance to $0.1 \%$ nitrite (Sau- } \\
\hline \multicolumn{11}{|l|}{ Tolerance to $0.2 \%$ picric acid } \\
\hline \multicolumn{11}{|l|}{ Resistance to $25 \mu \mathrm{g}$ of rifampin } \\
\hline per $\mathrm{ml} \ldots \ldots \ldots \ldots \ldots$ & + & + & + & + & + & + & + & + & + & + \\
\hline \multicolumn{11}{|l|}{ Resistance to $0.2 \% p$-aminosalic- } \\
\hline \multicolumn{11}{|l|}{ Resistance to $\mathrm{NH}_{2} \mathrm{OH} \cdot \mathrm{HCl}$} \\
\hline$(0.125 \mathrm{mg} / \mathrm{ml}) \ldots \ldots \ldots \ldots$ & + & + & + & + & + & + & + & + & + & + \\
\hline \multicolumn{11}{|l|}{ Resistance to $\mathrm{NH}_{2} \mathrm{OH} \cdot \mathrm{HCl}(0.25$} \\
\hline $\mathrm{mg} / \mathrm{ml}) \ldots \ldots \ldots \ldots \ldots$ & + & + & + & + & + & + & + & + & + & + \\
\hline \multicolumn{11}{|l|}{ Resistance to $10 \mu \mathrm{g}$ of $\mathrm{TCH}^{i}$ per } \\
\hline $\mathrm{ml} \ldots \ldots \ldots \ldots \ldots \ldots$ & + & + & + & + & + & + & + & + & + & + \\
\hline \multicolumn{11}{|l|}{ Resistance to $0.5 \mathrm{mg}$ of salicylate } \\
\hline per $\mathrm{ml} \ldots \ldots \ldots \ldots$ & + & + & + & + & + & + & + & + & + & + \\
\hline \multicolumn{11}{|l|}{ Resistance to $0.5 \mathrm{mg}$ of $p$-nitro- } \\
\hline benzoic acid per $\mathrm{ml} \ldots \ldots \ldots$ & + & + & + & + & + & + & + & + & + & + \\
\hline \multicolumn{11}{|l|}{ Resistance to $5 \mu \mathrm{g}$ of ethambutol } \\
\hline per $\mathrm{ml} \ldots \ldots \ldots \ldots$ & - & - & - & - & - & - & - & - & - & - \\
\hline
\end{tabular}


TABLE 1. Continued

\begin{tabular}{|c|c|c|c|c|c|c|c|c|c|c|}
\hline Character & $\begin{array}{c}\text { T- } \\
12109 \\
\end{array}$ & P2 & P2-R1 & $\begin{array}{c}\text { P2- } \\
\text { R1-N4 }\end{array}$ & $\begin{array}{c}\mathrm{P} 2- \\
\mathrm{R} 1 / \mathrm{N} 7 \\
\end{array}$ & 37013 & 37004 & 38013 & 38008 & 09003 \\
\hline Niacin production & - & - & - & - & - & - & - & - & - & - \\
\hline Tween hydrolysis at 14 days & + & + & + & + & + & + & + & + & t. & + \\
\hline Catalase (foam height, $>45 \mathrm{~mm}$ ) & + & + & + & + & + & + & + & + & + & + \\
\hline Salicylate degradation & - & - & - & - & - & - & - & - & - & - \\
\hline$p$-Aminosalicylate degradation & - & - & - & - & - & - & - & - & - & - \\
\hline Acetamidase & - & - & - & - & - & - & - & - & - & - \\
\hline Benzamidase & - & - & - & - & - & - & - & - & - & - \\
\hline Urease & - & - & - & - & - & - & - & - & - & - \\
\hline Isonicotinamidase & - & - & - & - & - & - & - & - & - & - \\
\hline Salicylamidase ... & - & - & - & - & - & - & - & - & - & - \\
\hline Allantoinase & - & - & - & - & - & - & - & - & - & - \\
\hline Succinamidase & - & - & - & - & - & - & - & - & - & - \\
\hline \multicolumn{11}{|l|}{ Growth at: } \\
\hline $28^{\circ} \mathrm{C}$ & + & + & + & + & + & + & + & + & + & + \\
\hline $37^{\circ} \mathrm{C}$ & + & + & + & + & + & + & + & + & + & + \\
\hline $45^{\circ} \mathrm{C}$ & - & - & - & - & - & - & - & - & - & - \\
\hline $52^{\circ} \mathrm{C}$ & - & - & - & - & - & - & - & - & - & - \\
\hline Mannose as C source ${ }^{b}$ & - & - & - & - & - & - & - & - & - & - \\
\hline Sucrose as C source ${ }^{b}$ & - & - & - & - & - & - & - & - & - & - \\
\hline Propylene glycol as C source ${ }^{b}$ & - & - & - & - & - & - & - & - & - & - \\
\hline Galactose as C source $^{h} \ldots \ldots$ & - & - & - & - & - & - & - & - & - & - \\
\hline Arabinose as C source ${ }^{b}$ & - & - & - & - & - & - & - & - & - & - \\
\hline Xylose as C source ${ }^{b}$ & - & - & - & - & - & - & - & - & - & - \\
\hline Rhamnose as C source" & - & - & - & - & - & - & - & - & - & - \\
\hline Trehalose as $\mathrm{C}$ source ${ }^{b}$ & - & - & - & - & - & - & - & - & - & - \\
\hline Inositol as $\mathrm{C}$ source $\mathrm{b}^{b}$ & - & - & - & - & - & - & - & - & - & - \\
\hline Mannitol as C source ${ }^{b}$ & - & - & - & - & - & - & - & - & - & - \\
\hline Sorbitol as C source ${ }^{b}$ & - & - & - & - & - & - & - & - & - & - \\
\hline Citrate as C source ${ }^{b}$ & - & - & - & - & - & - & - & - & - & - \\
\hline Succinate as C source ${ }^{b}$ & - & - & - & - & - & - & - & - & - & - \\
\hline Malate as C source ${ }^{h}$ & - & - & - & - & - & - & - & - & - & - \\
\hline Benzoate as C source $a$ & - & - & - & - & - & - & - & - & - & - \\
\hline Malonate as C source $b$ & - & - & - & - & - & - & - & - & - & - \\
\hline Fumarate as C source" & - & - & - & - & - & - & - & - & - & - \\
\hline Acid from glucose & - & - & - & - & - & - & - & - & - & - \\
\hline Acid from mannose & - & - & - & - & - & - & - & - & - & - \\
\hline Glutamate as $\mathrm{C}$ and $\mathrm{N}$ sources & - & - & - & - & - & - & - & - & - & - \\
\hline Serine as $\mathrm{C}$ and $\mathrm{N}$ sources & - & - & - & - & - & - & - & - & - & - \\
\hline Glucosamine as $\mathrm{C}$ and $\mathrm{N}$ sources & - & - & - & - & - & - & - & - & - & - \\
\hline Acetamide as $\mathrm{C}$ and $\mathrm{N}$ sources & - & - & - & - & - & - & - & - & - & - \\
\hline Benzamide as $\mathrm{C}$ and $\mathrm{N}$ sources & - & - & - & - & - & - & - & - & - & - \\
\hline $\begin{array}{l}\text { Monoethanolamine as } \mathrm{C} \text { and } \mathrm{N} \\
\text { sources }\end{array}$ & - & - & - & - & - & - & - & - & - & - \\
\hline Trimethylene diamine as $\mathrm{C}$ and & & & & & & & & & & \\
\hline $\mathrm{N}$ sources & - & - & - & - & - & - & - & - & - & - \\
\hline Benzamide as $\mathrm{N}$ source & - & - & - & - & - & - & - & - & - & - \\
\hline Nitrite as $\mathrm{N}$ source & - & - & - & - & - & - & - & - & - & - \\
\hline
\end{tabular}

${ }^{a}$ T-12109, $M$. gordonae ATCC 14470; 37004, M. triviale ATCC 19386; 38008, M. terrae W923; 37013, $M$. triviale ATCC 19387; 38013, M. terrae ATCC 15755; 09003, M. nonchromogenicum ATCC 19530.

${ }^{b}$ Nitrogen from ammoniac.

c TCH, Thiophene-2-carboxylic acid hydrazide.

done. After ultraviolet irradiation, ca. $17 \%$ of the surviving colonies appeared as scotochromogenic revertants, and S-type non-photochromogenic (pigmentless) mutants were isolated only at a rate of $1 / 10^{4}$ ( 2 per ca. 20,000 surviving colonies). The S-type non-photochromogenic mutants showed almost the same characters as the parent strain, except for colony pigmentation.

Throughout our experiments, it was impossible to isolate non-photochromogenic mutants directly from scotochromogenic parent bacteria.

It was observed that the mutation from $\mathrm{R}$ type photochromogens to R-type non-photo- 
TABLE 2. Change of catalase activity at various steps of mutation of M. gordonae T-12109 (ATCC 14470)

\begin{tabular}{|c|c|}
\hline Strain $^{a}$ & Foam height $(\mathrm{mm})^{b}$ \\
\hline$\ldots \ldots \ldots \ldots$ & $>130$ \\
\hline$\ldots \ldots$ & $>130$ \\
\hline$\ldots \ldots \ldots$ & $>130$ \\
\hline$\ldots \ldots \ldots \ldots$ & $>130$ \\
\hline$\ldots \ldots \ldots$ & $>130$ \\
\hline P2-R2 & 100 \\
\hline$\ldots \ldots$ & $>130$ \\
\hline P2-R1-N1 $\ldots \ldots$ & 72 \\
\hline P2-R1-N2 $\ldots \ldots$ & 53 \\
\hline P2-R1-N3 $\ldots \ldots$ & 67 \\
\hline P2-R1-N4 & 52 \\
\hline P2-R1-N5 & 64 \\
\hline P2-R3-N1 $\ldots$ & $>130$ \\
\hline P2-R3-N2 $\ldots \ldots$ & $>130$ \\
\hline P2-R3-N3 $\ldots \ldots$ & $>130$ \\
\hline P2-R3-N4 $\ldots \ldots$ & 59 \\
\hline P2-R3-N5 $\ldots \ldots$ & $>130$ \\
\hline $\mathrm{R} 1 \ldots \ldots \ldots$ & 83 \\
\hline$\ldots \ldots \ldots \ldots$ & 52 \\
\hline$\ldots \ldots \ldots$ & 92 \\
\hline $\mathrm{R} 1-\mathrm{P} 1$ & 50 \\
\hline $\mathrm{R} 1-\mathrm{P} 2$ & 61 \\
\hline R2-P1 $\ldots \ldots$ & 74 \\
\hline
\end{tabular}

"For designation of strains, refer to the text.

${ }^{b}$ Estimated by a semiquantitative method (9).

chromogens and the mutation from parent bacteria to R-type mutants frequently resulted in a decrease of catalase activity (Table 2).

The results of numerical classification, in which 88 characters were used, are shown in Fig. 2 as a dendrogram. Strain P2-R1 was included in the cluster of $M$. gordonae, whereas strains P2-R1-N4 and P2-R1-N7 were included in the cluster of the $M$. nonchromogenicum complex (M. nonchromogenicum, $M$. terrae, and $M$. triviale) (9). Strain P2-R1-N4 showed the highest matching coefficient to strain 37013 of $M$. triviale (97\%), and strain P2-R1-N7 showed the highest one to 38013 of $M$. terrae (94\%).

\section{DISCUSSION}

Comparison of pigments of $M$. gordonae and $M$. scrofulaceum from a genetic point of view. Previously, S. Tsukamura (11) reported that pigmentless (non-photochromogenic) mutants could be isolated from strains P5 and P6 of $M$. scrofulaceum after ultraviolet irradiation. In a recent study (unpublished), such mutants were isolated also from strains 12107 and 12108 of $M$. scrofulaceum. In contrast, nonphotochromogenic mutants have not been isolated directly from strains of $M$. gordonae. Only photochromogenic mutants have been isolated from these strains. Photochromogenic mutants have been isolated after ultraviolet irradiation not only from strain T-12109 but also from other two strains of $M$. gordonae, T-12353 (ATCC 23395) and T-12354 (ATCC 23397); non-photochromogenic mutants have not been isolated directly from parent, scotochromogenic bacteria (unpublished data).

These findings show that the genetic regulation of pigment formation of the scotochromogens $M$. gordonae and $M$. scrofulaceum is quite different. It is suggested that the pigments of $M$. scrofulaceum are formed in one way, which may be interrupted by the loss of one cistron. In contrast, the pigments of $M$. gordonae are formed in two ways: one in which light is required for pigment synthesis and another in which such a process is not required. It is also possible that the pigments are of two types: one formed in the dark and another formed only upon exposure to light. The colony pigmentation of the parent strain of $M$. gordonae is yellow or orange in the dark, and this is enhanced by exposure to light and becomes deep orange or

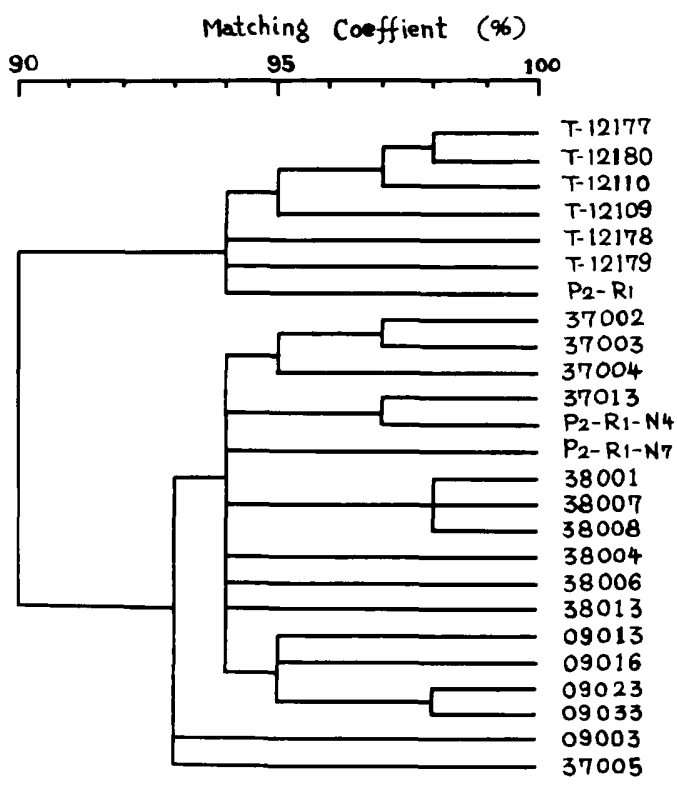

Fig. 2. Dendrogram showing the relationships among $M$. gordonae, $M$. triviale, $M$. terrae, $M$. nonchromogenicum, and mutants isolated from $M$. gordonae by ultraviolet irradiations. $M$. gordonae: $T$. 12177, T-12180, T-12110, T-12109, T-12178, and $T$. 12179. $M$. triviale: $37002,37003,37004,37013$ and 37005: $M$. terrae: 38001, 38007, 38008, 38004, 38006, and 38013. $M$. nonchromogenicum: 09013, 09016, 09023, 09033 and 09003. Mutant P2-R1 is included in the cluster of $M$. gordonae, and mutants P2-R1-N4 and P2-R1-N7 are included in the cluster of $M$. nonchromogenicum complex. 
reddish orange. The pigments of photochromogenic mutants are reddish. It is suggested that the pigments formed in the dark are different from those formed upon exposure to light.

Complex mutation. The phenomenon in which a mutation accompanies other mutations in the same cell is called "complex mutation." Complex mutations have been studied extensively in wheat (12), and the presence of such a complex mutation in mycobacteria has been reported by Tsukamura $(5,6)$. This phenomenon was observed in the present study. The mutation from R-type photochromogens to R-type nonphotochromogens was sometimes accompanied by loss of the ability to utilize certain carbon sources (Table 1).

Furthermore, it was also observed that the mutation from R-type photochromogens to Rtype non-photochromogens and the mutation from parent bacteria to R-type mutants frequently caused a decrease of catalase activity.

It is noteworthy that complex mutation did not occur in all cases but only in specified ones. For example, the mutation from S-type scotochromogens to S-type photochromogens and the mutation from S-type photochromogens to Stype non-photochromogens did not produce simultaneous changes of characters as observed in the present study, whereas the mutation from $\mathrm{R}$-type photochromogens to R-type non-photochromogens (from P-R to P-R-N) caused simultaneous alteration of other characters.

Definition of species. There is, at present, no decisive definition of the bacterial species concept. It may be defined, from viewpoints of numerical taxonomy, as a well-defined cluster (3) or, from viewpoints of immunology, as a group of organisms which share the same antigens (4). According to the former definition, strains P2-R1-N4 and P2-R1-N7 are included in the cluster of the $M$. nonchromogenicum complex (M. nonchromogenicum, $M$. terrae, and $M$. triviale) (9) and, therefore, are regarded as members of the complex. Strains P2-R1-N4 and P2R1-N7 show matching coefficients of 97 and $94 \%$ to strain 37013 (ATCC 19387) of M. triviale and to strain 38013 (ATCC 15755) of $M$. terrae, respectively. On the other hand, they show coefficients of 82 and $90 \%$ to strain T-12109 (ATCC 14470) of $M$. gordonae, from which they have been derived. This finding raises the question of whether $M$. triviale, $M$. terrae, and/or $M$. nonchromogenicum can be accurately differentiated from $M$. gordonae. However, a change of the species concept due to mutational studies as done here may result in great confusion. To avoid this, "species" should be defined as a well- recognizable cluster which is formed by "natural selection." The organisms of the $M$. nonchromogenicum complex belong to such a species.

In the present study, strains phenetically indistinguishable from $M$. triviale and/or $M$. terrae were isolated from the type strain of $M$. gordonae. However, mutants which show, like $M$. nonchromogenicum, nicotinamidase, pyrazinamidase, and $\beta$-galactosidase activities have not yet been obtained.

Strains P2, P2-R1, P2-R1-N4, and P2-R1-N7 have been deposited in the American Type Culture Collection, Rockville, Md., as ATCC 33005, ATCC 33006 , ATCC 33007 , and ATCC 33008 , respectively.

\section{REPRINT REQUESTS}

Address reprint requests to: Dr. M. Tsukamura, The National Chubu Hospital, Obu, Aichi, Japan 474.

\section{LTTERATURE CITED}

1. Bojalil, L. F., J. Cerbón, and A. Trujillo. 1962. Adan sonian classification of mycobacteria. J. Gen. Microbiol. 28:333-346.

2. Kubica, G. P., V. A. Silcox, J. O. Kilburn, R. W. Smithwick, R. E. Beam, W. D. Jones, and K. D. Stottmeier. 1970. Differential identification of mycobacteria. VI. Mycobacterium triviale Kubica sp. nov. Int. J. Syst. Bacteriol. 20:161-174.

3. Sneath, P. H. A. 1972. Computer taxonomy, p. 29-98. In Methods in microbiology, J. R. Norris and D. W. Ribbons (ed.), vol. 7A. Academic Press, London.

4. Stanford, J. L., and J. M. Grange. 1974. The meaning and structure of species as applied to mycobacteria. Tubercle 55:143-152.

5. Tsukamura, M. 1959. Studies on the complex mutation in bacteria. Reports I, II, and III. Jpn. J. Bacteriol. 14: 271-274, 425-428, 552-555.

6. Tsukamura, M. 1960. Studies on the complex mutation in bacteria. Report IV. Jpn. J. Bacteriol. 15:704-706.

7. Tsukamura, M. 1965. A group of mycobacteria from soil sources resembling nonphotochromogens (group 3). A description of Mycobacterium nonchromogenicum. Med. Biol. (Tokyo) 71:110-113.

8. Tsukamura, M. 1970. Appropriate name for tap water scotochromogens. Am. Rev. Respir. Dis. 102:643-644.

9. Tsukamura, M. 1976. Numerical classification of slowly growing mycobacteria. Int. J. Syst. Bacteriol. 26: 409-420.

10. Tsukamura, M. 1977. Source and infection route to humans of pathogenic mycobacteria other than tubercle bacilli. Kekkaku 52:261-267.

11. Tsukamura, S. 1963. Biological significance of pigments of mycobacteria. I. Artificial induction of pigmentless mutants from photochromogens and scotochromogens by ultraviolet irradiation. II. Correlation of pigment formation with the virulence. Jpn. J. Tuberc. 12:1-6.

12. Uchikawa, I. 1954. Spontaneous mutation, p. 587-614. In H. Kihara (ed.), Studies of wheat. Yokendo, Tokyo.

13. Wayne, L. G. 1966. Classification and identification of mycobacteria. III. Species within Group III. Am. Rev. Respir. Dis. 93:919-928.

14. Wayne, L. G. 1970. On the identity of Mycobacterium gordonae Bojalil and the so-called tap water scotochromogens. Int. J. Syst. Bacteriol. 20:149-153. 